\title{
'Socioeconomic position and survival after cervical cancer: influence of cancer stage, comorbidity and smoking among Danish women diagnosed between 2005 and 2010
}

\author{
E H Ibfelt ${ }^{*}, 1$, S K Kjær ${ }^{1,2}$, C Høgdall ${ }^{2}$, M Steding-Jessen ${ }^{1}$, T K Kjær $^{1}$, M Osler ${ }^{3}, C$ Johansen ${ }^{1}$, K Frederiksen $^{1}$ \\ and SO Dalton ${ }^{1}$ \\ ${ }^{1}$ Danish Cancer Society Research Center, Strandboulevarden 49, DK-2100 Copenhagen, Denmark; ${ }^{2}$ The Gynecologic Clinic, \\ The Juliane Marie Centre, Copenhagen University Hospital, Blegdamsvej 9, DK-2100 Copenhagen, Denmark and ${ }^{3}$ Research Center \\ for Prevention and Health, Glostrup University Hospital, Nordre Ringvej 57, DK-2600 Glostrup, Denmark
}

Background: In an attempt to decrease social disparities in cancer survival, it is important to consider the mechanisms by which socioeconomic position influences cancer prognosis. We aimed to investigate whether any associations between socioeconomic factors and survival after cervical cancer could be explained by socioeconomic differences in cancer stage, comorbidity, lifestyle factors or treatment.

Methods: We identified 1961 cases of cervical cancer diagnosed between 2005 and 2010 in the Danish Gynaecological Cancer database, with information on prognostic factors, treatment and lifestyle. Age, vital status, comorbidity and socioeconomic data were obtained from nationwide administrative registers. Associations between socioeconomic indicators (education, income and cohabitation status) and mortality by all causes were analysed in Cox regression models with inclusion of possible mediators. Median follow-up time was 3.0 years (0.01-7.0).

Results: All cause mortality was higher in women with shorter rather than longer education (hazard ratio (HR), 1.46; 1.20-1.77), among those with lower rather than higher income (HR, 1.32; 1.07-1.63) and among women aged $<60$ years without a partner rather than those who cohabited (HR, 1.60; 1.29-1.98). Socioeconomic differences in survival were partly explained by cancer stage and less by comorbidity or smoking (stage- and comorbidty- adjusted HRs being 1.07; 0.96-1.19 for education and 1.15; 0.86-1.52 for income).

Conclusion: Socioeconomic disparities in survival after cervical cancer were partly explained by socioeconomic differences in cancer stage. The results point to the importance of further investigations into reducing diagnosis delay among disadvantaged groups.

Socioeconomic factors such as education and income influence survival after a diagnosis and treatment of cervical cancer (Kogevinas and Porta, 1997; Jensen et al, 2008). Despite convincing evidence based on studies in several countries, more knowledge is needed about the underlying mechanisms by which socioeconomic position influences prognosis and how social and health-related aspects may interact. 'Socioeconomic position' refers to the social and economic factors that influence what positions individuals or groups hold within the structure of a society (Galobardes et al, 2006a).

\footnotetext{
*Correspondence: EH Ibfelt; E-mail: else@cancer.dk
}

Received 15 May 2013; revised 18 August 2013; accepted 19 August 2013; published online 12 September 2013

(c) 2013 Cancer Research UK. All rights reserved 0007-0920/13 
We previously showed that lower education was associated with advanced cervical cancer at the time of diagnosis (Ibfelt et al, 2012), suggesting that cancer stage partly explains social differences in survival. Apart from delayed diagnosis, more women with a lower social position also tend to have comorbid conditions and risky health behaviour, such as smoking, and these may influence incidence, comorbidity, treatment choice and survival after cervical cancer (Akers et al, 2007; Jensen et al, 2008; Louwman et al, 2010). Further socioeconomic differences in access to treatment have been suggested (Akers et al, 2007). Although this is less likely in a taxpaid public health care system; agreement about treatment, based on a doctor's recommendations given the patient's condition and on patient's understanding, may differ according to the patient's socioeconomic position.

Previous studies in this field involved area-level measures of socioeconomic position, with the risk of underestimating the effects of social factors; focused on ethnic differences or had limited clinical data on prognostic factors (Singh et al, 2004; Coker et al, 2006; Eggleston et al, 2006; Tammemagi, 2007; Movva et al, 2008; Brookfield et al, 2009; McCarthy et al, 2010; Lim and shing-Giwa, 2011), illustrating the need for studies based on individual level socioeconomic data and detailed clinical information, which we present here. In this population-based study we utilised access to data from administrative registers and a nationwide clinical database, and we investigated whether any association between socioeconomic position and overall survival after cervical cancer existed and further whether such association could be explained by socioeconomic differences in cancer stage, surgical treatment, comorbidity or lifestyle factors.

\section{MATERIALS AND METHODS}

Study population. The study population was identified from the Danish Gynaecological Cancer database (DGCD), which covers $96 \%$ of gynaecological cancer cases in Denmark and was established in 2005 (Høgdall and Nielsen, 2012). A total of 2141 cases of invasive cervical cancer diagnosed between 1 January 2005 and 31 December 2010 were retrieved. We excluded women if there was no registration date $(n=10)$, if there was no information on cancer stage $(n=11)$, if information on tumour histology was missing in the DGCD and in the nationwide Danish Pathology Register (DPR) and a diagnosis of cervical cancer could not be verified in the Danish Cancer Registry $(n=5)$. We also excluded women if they had immigrated to (because of missing information on socioeconomic position) or emigrated from (due to missing information on vital status) Denmark within 2 years before diagnosis $(n=30)$, if born before 1920 (before which date registers for socioeconomic data were incomplete) $(n=36)$, if information on three socioeconomic variables of interest (education, income and cohabitation status) were missing $(n=58)$ or if they were under 25 years of age and therefore considered not to have reached their final educational level or income $(n=30)$. This left a total of 1961 patients to be included in the current analyses.

Cancer characteristics and treatment. From the DGCD, we obtained the clinical cancer stage, tumour histology, type of surgical treatment and treating hospital and dates of staging and operation. All data were entered into the database by the hospital gynaecologists for clinical information and by a gynaecological pathologist for pathology. Staging was carried out according to the recommendations of the Fédération Internationale des Gynécologistes et Obstetristes (FIGO) (Quinn et al, 2006). Stage la cancers were staged from a cone biopsy, and more advanced stages were evaluated under general anaesthesia by a gynaecologist and a gynaecological oncologist (Dansk Gynækologisk Cancer Gruppe, 2011). Cancer stage was divided into four main FIGO stages for the descriptive statistics (I-IV). For 152 patients with missing information on tumour histology, histological information was searched in and retrieved from the DPR (Bjerregaard and Larsen, 2011), and the tumours were grouped into squamous cell carcinomas, adenocarcinomas and other types (including sarcomas and mixed types).

For a subgroup of patients with early-stage cancer (stage Ia1-Ib1) where operation is the recommended treatment strategy, we determined whether they received surgical treatment. As the chemo- and radiotherapy procedures recommended for more advanced cancer were underreported in the files of the DGCD and in the Danish National Patient register, NPR (Høgdall and Nielsen, 2012), we did not include information on primary oncologic treatment in the analyses. According to the Danish National clinical guidelines (Dansk Gynækologisk Cancer Gruppe, 2011), stage Ia cancer can be treated with a minimum of conisation. For cancer stage Ia with vascular invasion seen on cone biopsy and for stage Ib1 the strategy is radical hysterectomy or trachelectomy with lymph node dissection. In Denmark, treatment is centralised in five centres (Dansk Gynækologisk Cancer Gruppe, 2011). The type of surgical treatment registered in DGCD was validated in NPR and checked manually in the medical files of DGCD in case of missing data or operations deviating the expected operation for a given cervical cancer type. Manually checks were done if treatment information was missing $(n=22)$, if the operation type was registered as exploratory $(n=3)$ or as 'other operation type' $(n=12)$, and for patients with stage Ib1 if they were only registered with conisation $(n=11)$.

Other health-related factors. In order to estimate the burden of comorbidity, all somatic diagnoses other than cervical cancer were retrieved from the NPR, which contains data on all hospitalisations in Denmark since 1977 and all outpatient visits since 1995 (Lynge et al, 2011). Diagnoses were coded into a modified Danish version of the International Classification of Diseases version 8 (ICD-8) until 1993 and thereafter into ICD-10. We calculated the Charlson comorbidity index (CCI), which covers 19 selected conditions scored from 1 to 6 by degree of severity (Charlson et al, 1987), and all clinical conditions were summed until 1 year before the cancer diagnosis. Comorbidity was grouped into 0 (none), 1 and 2 and 3 or more.

Information on lifestyle factors at the time of diagnosis was obtained from the DGCD. Smoking was categorised into 'never smokers', ex-smokers and current smokers; and body mass index (BMI) into normal (18.5-24.9), underweight $(<18.5)$, overweight $(25-29.9)$ and obese $(\geqslant 30)$ for the analyses.

Socioeconomic indicators. Information on socioeconomic factors was obtained from the Danish Civil Registration System and from registers on education and income kept by Statistics Denmark, which contain data for each individual, updated each year (Baadsgaard and Quitzau, 2011; Jensen and Rasmussen, 2011; Pedersen, 2011). Information on indicators 2 years before cancer diagnosis was used to minimise any reverse effect of early disease symptoms on socioeconomic position. Three indicators were selected to cover different aspects of social influence on health: knowledge-related assets (education), material resources (income) and social support (cohabitation status) (Lund et al, 2002; Galobardes et al, 2006a).

Highest attained level of education was categorised into short (7 or 9 years of mandatory primary school for patients born before and after 1958, respectively), medium (8 or 10-12 years, latest grade of primary school, secondary school or vocational education) and high ( $>12$ years of education). Disposable income was household income per person after taxation and interest, adjusted for the number of people in the household and deflated according to 2000 value of the Danish crown by the formula from the Danish ministry of Finance: deflated household income/no. of persons in 
household ${ }^{0.6}$. It was categorised into quartiles of the national gender-specific disposable household income per person distribution: lowest (1st quartile), middle (2nd-3rd quartile) and highest (4th quartile). Cohabitation status was categorised as living with a partner (married or cohabiting) and living without a partner (single, widowed or divorced), as mortality patterns were similar for these groups. Cohabiting was defined as, in the absence of marriage, two people of the opposite sex, over the age of 16 years, with a maximum 15 years of age difference, living at the same address with no other adult in residence.

Survival. Data on age, emigration and vital status at 30 November 2011 were retrieved from the Civil Registration System (Pedersen, 2011).

Statistical analysis. Associations between socioeconomic factors and all cause mortality were analysed in survival models, and confounders and mediators were identified in a diagram of hypothesised causal relations (Figure 1). For the survival analyses, a four-step model was used in accordance with the diagram: In model 1, associations between each socioeconomic indicator and mortality were calculated with adjustment for age; in model 2, relevant socioeconomic confounders were adjusted for (i.e., income was adjusted for education and cohabitation status); in models 3 and 4 , comorbidity and cancer stage were entered stepwise to analyse whether these factors mediate the association between socioeconomic factors and mortality. Because of a high proportion of missing in the lifestyle variables, in two sets of subgroup analyses, the first including only women for whom information was available on smoking (exclusion of $n=229$ ) and the second including only women for whom we had information on both smoking and BMI (exclusion of $n=289$ ), smoking status and BMI were entered stepwise. In a sensitivity analysis, we re-ran the main models (1-4) in the subgroups to ensure that the extent to which comorbidity and stage explained the survival differences was equal to that in the main results.

Cox regression analysis was used to estimate hazard rate ratios (HRs) for death by all causes. Patients were followed from the date of diagnosis (either date of diagnostic staging or date of operation if staging date was not registered) in DGCD until date of death, emigration or end of follow-up. Time since diagnosis was used as the underlying time scale. Two-sided 95\% confidence intervals (CIs) were calculated for the HRs with the Wald test of the Cox regression parameter. The assumptions of proportional hazards were tested graphically for each of the covariates. When reviewed graphically the effect of the three socioeconomic factors was equal over time from diagnosis, except for the graphs for income that were crossing at about 4.5 months after diagnosis; however, hazard ratios (HRs) for income was tested not significantly different before and after this time. Age was modelled as a continuous factor. Adjustment for cancer stage was done allowing separate underlying hazards for each stage (FIGO Ia1-IVb). All models were adjusted for a cluster effect of diagnosis and treatment at the same hospital with the robust sandwich covariance estimate.

We hypothesised that interactions between socioeconomic and health-related factors might exist and figured that mortality might be higher in patients who were both socially disadvantaged and had high age, severe comorbidity or advanced cancer. Therefore, effect modification between each of the three socioeconomic variables with age (in four groups), stage (four FIGO stages) and comorbidity (CCI $0,1,2$ and $3+$ ) were tested one at a time with age in the model using the Wald test statistics.

For the treatment outcome, whether receiving surgical treatment was analysed descriptively for a subgroup of 1056 patients with early cancer.

The analyses were carried out in SAS 9.3 with the PHREG procedures, and $P<0.05$ was considered statistically significant.

\section{RESULTS}

The 1961 cervical cancer patients were followed up for a median of $3.0(0.01-7.0)$ years, during which time 476 patients (24\%) died by all causes. More deaths during follow-up were observed among women who were older, had shorter education, had lower disposable income, lived without partner, had advanced cancer stage, had comorbid conditions, were smokers, were underweight, had oncological treatment or were categorised as 'unknown' for any indicator (Table 1).

Table 2 specifies the distribution of comorbid conditions among the 359 women with a comorbidity score of $\geqslant 1$.

Of 1056 patients with cancer stage (Ia1-Ib1), 555 underwent radical hysterectomy with lymphadenectomy, 252 a simple hysterectomy, 70 a trachelectomy, 140 only a conisation, 2 patients had a laparoscopic lymphadenectomy because of positive lymph nodes at PET/CT, 1 was operated for cancer in the cervical stump (previous hysterectomy for benign condition) and 32 were referred to primary oncologic treatment because of more advanced disease found before planned surgery, in the following disease course or because of comorbidity. Four patients (all stage $\mathrm{Ib} 1$ ) received no treatment or only conisation because of patient decline or severe comorbidity (Table 1 ).

Table 3 (model 2) shows that education and income were significantly associated with survival, the adjusted HR for short education being $1.46(1.20-1.77)$ and that for lower income being

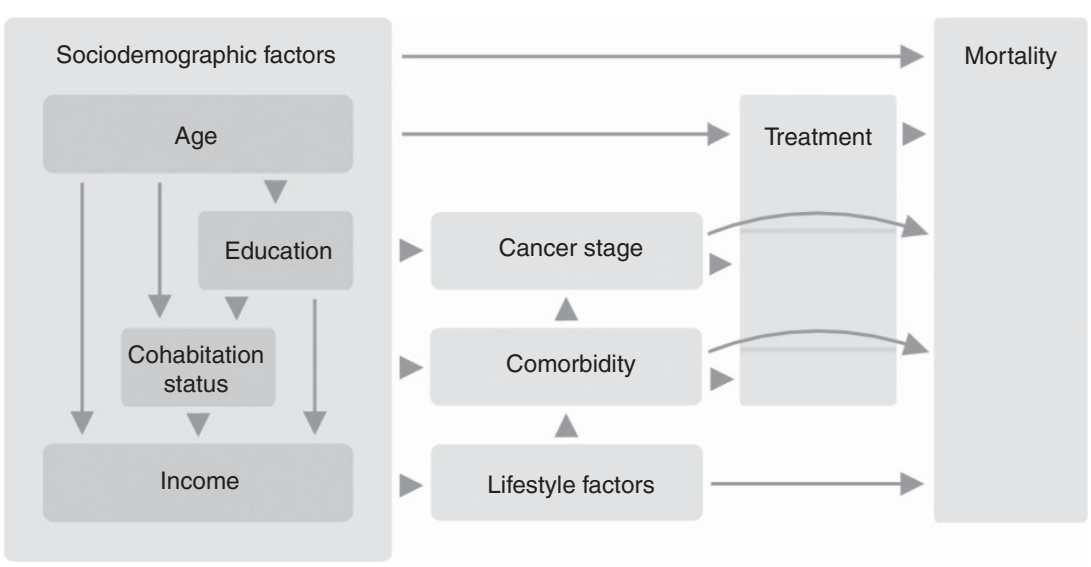

Figure 1. Hypothesised causal relations between sociodemographic factors, cancer stage, treatment, comorbidity, lifestyle factors and mortality. 
Table 1. Descriptive statistics of 1961 Danish patients with cervical cancer diagnosed between 2005 and 2010

\begin{tabular}{|c|c|c|}
\hline Characteristics & $\begin{array}{c}\text { All, } \mathbf{N}=1961 \\
(\%)\end{array}$ & $\begin{array}{l}\text { No. of deaths during } \\
\text { follow-up, } n(\%)\end{array}$ \\
\hline \multicolumn{3}{|l|}{ Age (years) ${ }^{a}$} \\
\hline $\begin{array}{l}25-39 \\
40-59 \\
60-79 \\
\geqslant 80\end{array}$ & $\begin{array}{l}617(32) \\
754(38) \\
489(25) \\
101(5)\end{array}$ & $\begin{aligned} & 45(7) \\
& 138(18) \\
& 221(45) \\
& 72(71)\end{aligned}$ \\
\hline \multicolumn{3}{|l|}{ Level of education ${ }^{b}$} \\
\hline $\begin{array}{l}\text { Short ( } 7 \text { or } 9 \text { years) } \\
\text { Medium ( } 8 \text { or } 10-12 \text { years) } \\
\text { Higher ( } \geqslant 12 \text { years) } \\
\text { Missing }\end{array}$ & $\begin{array}{r}416(21) \\
1025(52) \\
473(24) \\
47(2)\end{array}$ & $\begin{array}{r}176(42) \\
205(20) \\
74(16) \\
21(45)\end{array}$ \\
\hline \multicolumn{3}{|l|}{ Disposable income ${ }^{b}$} \\
\hline $\begin{array}{l}\text { Lowest (1st quartile) } \\
\text { Middle (2nd-3rd quartiles) } \\
\text { Highest (4th quartile) } \\
\text { Missing }\end{array}$ & $\begin{array}{c}560(28) \\
921(47) \\
400(21) \\
80(4)\end{array}$ & $\begin{array}{r}162(28) \\
215(23) \\
76(19) \\
23(29)\end{array}$ \\
\hline \multicolumn{3}{|l|}{ Cohabitation status $^{\mathrm{b}}$} \\
\hline $\begin{array}{l}\text { Married or cohabiting } \\
\text { Single, widowed or } \\
\text { divorced }\end{array}$ & $\begin{array}{r}1216(62) \\
745(38)\end{array}$ & $\begin{array}{l}241(20) \\
235(32)\end{array}$ \\
\hline \multicolumn{3}{|l|}{ Year of diagnosis } \\
\hline $\begin{array}{l}2005 \\
2006 \\
2007 \\
2008 \\
2009 \\
2010\end{array}$ & $\begin{array}{l}336(17) \\
335(17) \\
333(17) \\
310(16) \\
348(18) \\
299(15)\end{array}$ & $\begin{array}{r}111(33) \\
85(25) \\
99(30) \\
76(25) \\
68(20) \\
37(12)\end{array}$ \\
\hline
\end{tabular}

Tumour histology

\begin{tabular}{|l|r|r|}
\hline Squamous cell carcinoma & $1477(76)$ & $353(24)$ \\
Adenocarcinoma & $366(19)$ & $76(21)$ \\
Other & $99(5)$ & $34(34)$ \\
Unknown & $19(1)$ & $13(68)$ \\
\hline
\end{tabular}

\section{Cancer stage (FIGO)}

\begin{tabular}{|l|c|c|}
\hline I & $1143(58)$ & $83(7)$ \\
II & $430(22)$ & $129(30)$ \\
III & $253(13)$ & $151(60)$ \\
IV & $135(7)$ & $113(84)$ \\
\hline
\end{tabular}

\begin{tabular}{|l|r|r|}
\hline \multicolumn{2}{|l|}{ Comorbidity $(\mathrm{CCl} \text { score })^{\mathbf{c}}$} \\
\hline 0 & $1602(82)$ & $315(20)$ \\
1 & $215(11)$ & $83(39)$ \\
2 & $89(5)$ & $40(45)$ \\
$\geqslant 3$ & $55(3)$ & $38(69)$ \\
\hline
\end{tabular}

\section{Smoking status ${ }^{a}$}

\begin{tabular}{|l|r|r|}
\hline Never & $781(40)$ & $141(18)$ \\
Former smoker & $297(15)$ & $58(19)$ \\
Current smoker & $654(33)$ & $191(29)$ \\
Unknown & $229(12)$ & $86(38)$ \\
\hline Body mass index (BMI) ${ }^{a}$ \\
\hline Underweight (<18.5) & $88(4)$ & $42(48)$ \\
Normal (18.5-24.9) & $994(51)$ & $213(21)$ \\
Overweight (25-29.9) & $480(25)$ & $98(20)$ \\
Obesity ( $\geqslant 30)$ & $302(15)$ & $72(24)$ \\
Unknown & $97(5)$ & $52(54)$ \\
\hline
\end{tabular}

\section{Table 1. (Continued)}

\begin{tabular}{|c|c|c|}
\hline Characteristics & $\begin{array}{c}\text { All, } \mathbf{N}=1961 \\
(\%)\end{array}$ & $\begin{array}{l}\text { No. of deaths during } \\
\text { follow-up, } n(\%)\end{array}$ \\
\hline \multicolumn{3}{|c|}{ Treatment (cancer stages la1-lb1) $(n=1056)$} \\
\hline $\begin{array}{l}\text { Radical hysterectomy } \\
\text { Hysterectomy } \\
\text { Trachelectomy } \\
\text { Conisation } \\
\text { Other types of operation } \\
\text { No operation } \\
\text { Oncological treatment } \\
\text { (referral) }\end{array}$ & $\begin{array}{c}555(53) \\
252(24) \\
70(7) \\
140(12) \\
3(0) \\
4(4) \\
32(3)\end{array}$ & $\begin{array}{c}39(7) \\
16(6) \\
0 \\
3(2) \\
0 \\
0 \\
9(27)\end{array}$ \\
\hline \multicolumn{3}{|c|}{$\begin{array}{l}\text { Abbreviations: } \mathrm{CCl}=\text { Charlson comorbidity index; FIGO=Fédération Internationale des } \\
\text { Gynécologistes et Obstetristes. } \\
\text { a Measured at the time of diagnosis. } \\
\text { b } \\
\text { into short factors were included } 2 \text { years before cancer diagnosis. Education was categorised } \\
\text { into mandatory primary school education for patients born before or } \\
\text { after 1958, respectively), medium ( } 8 \text { or 10-12 years, latest grade of primary school, } \\
\text { secondary school or vocational education) and higher ( } \geqslant 12 \text { years of education). Income was } \\
\text { categorised into lowest (1st quartile), middle (2nd-3rd quartiles) and highest (4th quartile) } \\
\text { 'Cumulated from } 1977 \text { and until } 1 \text { year before cancer diagnosis. }\end{array}$} \\
\hline
\end{tabular}

1.32 (1.07-1.63). Significant interactions were found between age and cohabitation status $(P<0.0001)$, age and income $(P<0.0001)$ and stage and income $(P<0.0001)$. For cohabitation and income, the results were shown separately for age $<60$, and the adjusted HR of women aged $<60$ years living without a partner was significantly increased 1.60 (1.29-1.98) over that for cohabiting women. The effect of income declined from lower to higher age groups. The ageadjusted HRs for income in categories of age were $<40$ years (HR, 1.92 ; $0.70-5.31$ ), $40-60$ years (HR, $1.69 ; 1.40-2.05), 60-80$ years (HR, $1.55 ; 1.11-2.19)$ and $\geqslant 80$ years (HR, $1.36 ; 0.49-3.76)$. The effect of income also declined from lower to higher stages; and among a small group of patients with stage IV cancer, there was no survival difference by income (stratified results are not shown).

Inclusion of comorbidity had a minor influence on the associations between socioeconomic factors and survival. When cancer stage was entered, the HR for shorter rather than higher education was $1.07(0.96-1.19)$, the HR for lowest rather than highest income was $1.15(0.86-1.52)$ and the HR for women aged $<60$ years living without a partner was $1.42(1.16-1.74)$ (Table 3, models 3 and 4).

When smoking was included in the subgroup analysis, the estimated HR for women with shorter education was 0.89 (0.75$1.05)$, for lower income was $0.95(0.74-1.21)$ and for living without a partner was $1.24(1.01-1.52)$ as compared with women with longer education, higher income and cohabiting women, respectively (Table 3, subgroup results). Inclusion of BMI did not change these estimates further; for example, the HR for women with shorter education was 0.89 (0.76-1.05) (data not shown). However, the age-adjusted association between each socioeconomic factor and mortality was weaker in these subgroups than in the main analysis. The age-adjusted HRs were 1.36 (1.07-1.74) for short education and $1.29(0.98-1.71)$ for lowest income, but similar for cohabitation status; and these estimates were slightly lower after exclusion of women for whom BMI information was missing. The size of the extent to which comorbidity and stage influenced the relations was close to those in the main analysis (data not shown).

\section{DISCUSSION}

In this nationwide study of women with cervical cancer, short education, lower income and living without a partner were related 


\begin{tabular}{|c|c|c|}
\hline Disorder & $\begin{array}{c}\mathrm{CCl} \\
\text { weight }^{\mathrm{a}}\end{array}$ & $\begin{array}{l}\text { No. of } \\
\text { patients }\end{array}$ \\
\hline Myocardial infarction & 1 & 23 \\
\hline Congestive heart failure & 1 & 12 \\
\hline Peripheral vascular disease & 1 & 41 \\
\hline Cerebrovascular disease & 1 & 67 \\
\hline Dementia & 1 & 3 \\
\hline Chronic pulmonary disease & 1 & 98 \\
\hline Connective tissue disease & 1 & 39 \\
\hline Ulcer disease & 1 & 40 \\
\hline Mild liver disease & 1 & 18 \\
\hline Diabetes type 1 and type 2 & 1 & 44 \\
\hline Hemiplegia & 2 & 1 \\
\hline Moderate to severe renal disease & 2 & 20 \\
\hline $\begin{array}{l}\text { Diabetes type } 1 \text { and type } 2 \text { with end-organ } \\
\text { damage }\end{array}$ & 2 & 18 \\
\hline Any tumour (other than cervical) & 2 & 52 \\
\hline Leukaemia & 2 & 1 \\
\hline Lymphoma & 2 & 6 \\
\hline Moderate to severe liver disease & 3 & 1 \\
\hline Metastatic solid tumour & 6 & 9 \\
\hline AIDS & 6 & 0 \\
\hline \multicolumn{3}{|c|}{$\begin{array}{l}\text { aWeights for each condition that a patient has; the total is the score. For example: chroni } \\
\text { pulmonary (1) and lymphoma (2)=total score (3). } \\
\text { b On the basis of data from the Danish National Patient Register. }\end{array}$} \\
\hline
\end{tabular}

to shorter survival. These socioeconomic differences in survival were explained mostly by cancer stage and to a lesser extent by smoking and comorbidity, leaving only a tendency to differences in survival by cohabitation status, after adjustment. As only a few patients with early-stage cancer were not given first-line treatment, we suggest that there are no socioeconomic differences in who undergo first-line treatment for early cervical cancer.

Significant socioeconomic differences in survival was found in most other cohorts of cervical cancer patients, higher mortality being associated with a shorter education, lower income; indicators of lower social position or living in areas with poverty (Singh et al, 2004; Eggelston et al, 2006; Brookfield et al, 2009; Tan et al 2009; McCarthy et al, 2010; Li et al, 2012; Simard et al, 2012) and being unmarried or living alone (Kvikstad and Vatten, 1996; Howell et al, 1999; McCarthy et al, 2010; Patel et al, 2010; Li et al, 2012). Although there are exceptions in studies using area-level data, a composite social measure and with focus on older patients (Coker et al, 2006; Lim and shing-Giwa, 2011).

With regard to possible mediating factors, we found that most of the association between education or income and survival was due to cancer stage. In comparison, two studies from the USA found a tendency to survival disparities by community poverty level after adjustment for cancer characteristics and under treatment (HR, 1.21; 0.97-1.51) (Brookfield et al, 2009) and 1.20 (0.88-1.64) (McCarthy et al, 2010). Whereas another study showed considerable survival differences by area-level socioeconomic status after adjustment for stage (HR, 1.9; 1.6-2.3) (Eggleston et al, 2006); however, data on stage were missing for $17 \%$ of women and stage was dichotomised with the possibility of selection bias and residual mediation. Further it was found that differences in survival by marital status varied by stage, the largest differences being for patients with early-stage cancer (Patel et al, 2010). We found a similar nonsignificant tendency to an effect modification between cohabitation status and stage (data not shown). Studies in Norwegian and US patients showed that survival differences between single and married women were partly explained by stage (never married, HR, 1.48; 1.05-2.09; divorced, 1.25, 0.99-1.57) (Kvikstad et al, 1995; Kvikstad and Vatten, 1996) and by both stage and treatment (HR, 1.15; 1.02-1.26) (Howell et al, 1999). We also found a small elevated mortality among single rather than married or cohabiting women after adjustment for important prognostic factors. One suggestion is that this tendency is due to differences in access to or compliance with oncological treatment, which we could not account for in our data, because social support may be more critical for patients receiving a series of treatments than for those whose cancer is managed definitively by surgery (Patel et al, 2010). Another possible reason is that these patients are somehow more vulnerable from the beginning of treatment with respect to unmeasured health-related factors that are not captured in the comorbidity index.

The finding that cancer stage is the most important factor affecting socioeconomic differences in cervical cancer survival points to explanations such as patients or primary care doctors delay due to lower screening participation, delayed health careseeking behaviour, less reporting of symptoms or late referral to specialist care (Corner and Brindle, 2011), which is supported by findings of social disparities in cervical cancer screening and in symptom recognition and awareness (Rodvall et al, 2005; Seidel et al, 2009; Low et al, 2012). However, our previous study on same data showed that lower screening participation only explained a relatively small part of the socioeconomic differences in cervical cancer diagnosis stage (Ibfelt et al, 2012).

In our study, smoking appeared to have a greater impact on socioeconomic differences in survival than comorbidity. In comparison, comorbidity was found to have no impact on the social disparities in mortality after cervical cancer in a Swedish population ( $\mathrm{Li}$ et al, 2012); whereas smokers compared with nonsmokers had a significantly higher all cause mortality (35\%, age-, stage- and treatment-adjusted) among US cervical cancer patients (Coker et al, 2009), corresponding to our results. With the relatively low age of this patient group, and most patients diagnosed in early cancer stages, comorbidity seems to have a limited influence on the survival disparities. On the other hand, it might be considered that the comorbidity index used is not sensitive enough to capture the burden of comorbidity; as CCI scores were calculated from in- and outpatient hospital contacts, diagnosis treated solely at general practitioner were not counted in. However, the index conditions are severe and would most likely be causes of contact with a hospital. Further, treatment opportunities have improved as the CCI weights were constructed; and also, with data based on NPR discharge diagnosis no differentiation was made between mildest $v s$ severe cases of a given disorder. However, the clear stepwise survival difference between CCI scores 0 to $\geqslant 3$ as shown descriptively indicates that the $\mathrm{CCI}$ is valid for measuring the burden of comorbid disease in this patient group.

Smoking might be a proxy for comorbidity that is not captured in the index. Smoking-related comorbidity was frequent in this patient group (Table 2), but being a smoker could also be associated with reduced general health status due to both smoking and other lifestyle factors. Body mass index measured at the time of diagnosis did not appear to mediate the association, and alcohol consumption was underreported in the DGCD (data missing for $81 \%$ ). The analyses of the impact of smoking were limited to women for whom information was available and excluding those with the highest mortality, which may have increased the apparent impact of smoking. We assumed, however, that smoking, which 
Table 3. Associations between socioeconomic factors and mortality from all causes with inclusion of the potential mediators (comorbidity and cancer stage), among 1961 Danish women with cervical cancer diagnosed 2005-2010, and with inclusion of smoking for a subgroup of 1696 women

\begin{tabular}{|c|c|c|c|c|c|}
\hline & $\begin{array}{c}\text { Model } 1 \\
\text { Adjustment for } \\
\text { age } \\
\text { HR }(95 \% \mathrm{Cl})\end{array}$ & $\begin{array}{c}\text { Model } 2 \\
\text { Adjusted } \\
\text { HR }(95 \% \mathrm{Cl})^{\mathrm{a}}\end{array}$ & $\begin{array}{c}\text { Model } 3 \\
\text { Adjusted }^{\mathbf{b}}+\text { comorbidity } \\
\text { HR }(95 \% \mathrm{Cl})\end{array}$ & $\begin{array}{c}\text { Model } 4 \\
\text { Adjusted }^{\mathrm{c}}+\text { cancer } \\
\text { stage HR }(95 \% \mathrm{Cl})\end{array}$ & $\begin{array}{c}\text { Subgroup results } \\
\text { Adjusted }+ \text { smoking }^{\text {d }} \\
\text { status }^{d} \\
\text { HR }(95 \% \mathrm{Cl})\end{array}$ \\
\hline Level of education $(n=1914)$ & & & & & $(n=1696)$ \\
\hline Higher & 1 & 1 & 1 & 1 & 1 \\
\hline Medium & $1.19(0.92-1.54)$ & $1.19(0.92-1.54)$ & $1.20(0.89-1.62)$ & $1.03(0.78-1.35)$ & $0.91(0.62-1.33)$ \\
\hline Short & $1.46(1.20-1.77)$ & $1.46(1.20-1.77)$ & $1.44(1.19-1.75)$ & $1.07(0.96-1.19)$ & $0.89(0.75-1.05)$ \\
\hline Cohabitation status $(n=1961)$ & & & & & $(n=1696)$ \\
\hline \multicolumn{6}{|l|}{ All } \\
\hline Married or cohabiting & 1 & 1 & 1 & 1 & 1 \\
\hline Single, widowed, divorced & $1.11(1.00-1.23)$ & $1.08(0.97-1.20)$ & $1.01(0.89-1.14)$ & $0.97(0.87-1.09)$ & $1.02(0.90-1.16)$ \\
\hline \multicolumn{6}{|l|}{ Age $<60$} \\
\hline Married or cohabiting & 1 & 1 & 1 & 1 & 1 \\
\hline Single, widowed, divorced & $1.58(1.26-1.98)$ & $1.60(1.29-1.98)$ & $1.59(1.28-1.98)$ & $1.42(1.16-1.74)$ & $1.24(1.01-1.52)$ \\
\hline Disposable income $(n=1881)$ & & & & & $(n=1634)$ \\
\hline \multicolumn{6}{|l|}{ All } \\
\hline Highest (4th quartile) & 1 & 1 & 1 & 1 & 1 \\
\hline Middle (2nd-3rd quartile) & $1.15(1.02-1.31)$ & $1.09(0.94-1.25)$ & $1.08(0.97-1.20)$ & $0.99(0.87-1.12)$ & $0.90(0.72-1.11)$ \\
\hline Lowest (1st quartile) & $1.44(1.17-1.76)$ & $1.32(1.07-1.63)$ & $1.34(1.12-1.62)$ & $1.15(0.86-1.52)$ & $0.95(0.74-1.21)$ \\
\hline \multicolumn{6}{|l|}{ Age $<60$} \\
\hline Highest (4th quartile) & 1 & 1 & 1 & 1 & 1 \\
\hline Lowest (1st quartile) & $1.90(1.45-2.51)$ & $1.59(1.29-1.95)$ & $1.56(1.22-1.97)$ & $1.08(0.86-1.35)$ & $0.80(0.64-1.00)$ \\
\hline \multicolumn{6}{|c|}{$\begin{array}{l}\text { Abbreviations: } \mathrm{Cl}=\text { confidence interval; } \mathrm{HR}=\text { hazard ratio; } \mathrm{FIGO}=\text { Fédération Internationale des Gynécologistes et Obstetristes. } \\
\text { a Education adjusted for age; cohabitation status adjusted for age and education; income adjusted for age, education and cohabitation status. } \\
\text { b Adjustments as in model } 2 \text { and additionally adjusted for Charlson comorbidity index. } \\
{ }^{c} \text { Adjustments as in model } 3 \text { and additionally adjusted for cancer stage (FIGO). } \\
\text { d Subgroup results including patients with information on smoking registered, results adjusted for smoking status, comorbidity and cancer stage (FIGO). }\end{array}$} \\
\hline
\end{tabular}

affects healing after surgery and radiotherapy, and to some extent comorbidity, influences social differences in survival after cervical cancer, secondary to the influence of cancer stage.

Recent studies from the US found diverging effects of marital status and neighbourhood income level on treatment outcomes (Katz et al, 2000; Torres et al, 2009; Patel et al, 2010). In our study, the absolute number of patients with early cancer stage who did not receive first-line surgery was small, and all but four patients were referred to chemotherapy primarily for the findings of more advanced cancer or poor health condition. Thus, for this outcome there was no purpose of looking into socioeconomic differences, and we therefore suggest that there are no socioeconomic differences in who received first-line treatment for early cervical cancer.

Important strengths of the study are linkage of data in nationwide, population-based administrative registers by the unique Danish personal identification number, which minimised selection bias and misclassification of disease-related, lifestyle and socioeconomic information, whereas area-based measures were used in most previous studies on this topic, with a risk for misclassifying socioeconomic position (Galobardes et al, 2006b). In addition, the use of cohabitation status rather than marital status covered social influences from non-marital relationships and thereby minimised misclassification of social support from a partner (Lund et al, 2002). Short comings of the study include missing information on oncological treatment and the basis for estimating burden of comorbidity; however, we suggest that this leave minor bias to the study results. Lastly, we used a standard method to examine the pathways from exposure through intermediate factors (stage, comorbidity and so on) to the mortality outcome, where we conditioned on these factors in regression analyses. In recent years, methods for a more precise quantification of mediating effects have been developed with the advantages of a more direct causal interpretation and with mathematical consistency (Lange and Hansen, 2011). However, such models have mostly been applied to problems of a more biological nature, whereas socioeconomic exposures could be measured in a number of ways. The pathways from socioeconomic exposures to outcomes are rarely simple, and many mediators and confounders could be identified. Also, to quantify a precise effect of a mediating variable (with narrow confidence limits) requires larger sample sizes than was available here.

In conclusion, socioeconomic differences in survival after cervical cancer were found in a population where ethnic homogeneity and universal access to health care exist. These socioeconomic differences were mostly explained by cancer stage and to a lesser extent by comorbidity and smoking. The results indicate the need for further investigations on how to reduce delays in diagnosis for disadvantaged groups and the importance of smoking prevention aimed at these groups. Finally, in general, health care professionals should pay attention to socially disadvantaged patients and patients without close supportive relationships during the cancer trajectory.

\section{ACKNOWLEDGEMENTS}

We thank the Danish Gynaecological Cancer Group for allowing us to use basic clinical data from its database. 


\section{CONFLICT OF INTEREST}

SKK received advisory board and speaker's fees and scientific research grants through her institution from Sanofi Pasteur MSD and Merck.

\section{REFERENCES}

Akers AY, Newmann SJ, Smith JS (2007) Factors underlying disparities in cervical cancer incidence, screening, and treatment in the United States. Curr Probl Cancer 31: 157-181.

Baadsgaard M, Quitzau J (2011) Danish registers on personal income and transfer payments. Scand J Public Health 39: 103-105.

Bjerregaard B, Larsen OB (2011) The Danish Pathology Register. Scand J Public Health 39: 72-74.

Brookfield KF, Cheung MC, Lucci J, Fleming LE, Koniaris LG (2009) Disparities in survival among women with invasive cervical cancer: a problem of access to care. Cancer 115: 166-178.

Charlson ME, Pompei P, Ales KL, MacKenzie CR (1987) A new method of classifying prognostic comorbidity in longitudinal studies: development and validation. J Chronic Dis 40: 373-383.

Coker AL, DeSimone CP, Eggleston KS, Hopenhayn C, Nee J, Tucker T (2009) Smoking and survival among Kentucky women diagnosed with invasive cervical cancer: 1995-2005. Gynecol Oncol 112: 365-369.

Coker AL, Du XL, Fang S, Eggleston KS (2006) Socioeconomic status and cervical cancer survival among older women: findings from the SEERMedicare linked data cohorts. Gynecol Oncol 102: 278-284.

Corner J, Brindle L (2011) The influence of social processes on the timing of cancer diagnosis: a research agenda. J Epidemiol Community Health 65 $477-482$.

Dansk Gynækologisk Cancer Gruppe (2011) Retningslinier for visitation, diagnostik, behandling og kontrol af cervixcancer. København 2011. (The official Danish Clinical Guidelines for treatment of cervical cancer, Copenhagen).

Eggleston KS, Coker AL, Williams M, Tortolero-Luna G, Martin JB, Tortolero SR (2006) Cervical cancer survival by socioeconomic status, race/ethnicity, and place of residence in Texas, 1995-2001. J Womens Health (Larchmt) 15: 941-951.

Galobardes B, Shaw M, Lawlor DA, Lynch JW, Davey SG (2006a) Indicators of socioeconomic positionpart 1J Epidemiol Community Health 60: 7-12.

Galobardes B, Shaw M, Lawlor DA, Lynch JW, Davey SG (2006b) Indicators of socioeconomic positionpart 2J Epidemiol Community Health 60: 95-101.

Høgdall C, Nielsen ML (2012) Year report 2009/2010. The Nationwide Danish Gynecologic Cancer Database for cancers in the ovaries, uterus and cervix. (in Danish. No abstract available). Copenhagen, Lægeforeningens forlag.

Howell EA, Chen YT, Concato J (1999) Differences in cervical cancer mortality among black and white women. Obstet Gynecol 94: 509-515.

Ibfelt E, Kjaer SK, Johansen C, Hogdall C, Steding-Jessen M, Frederiksen K, Frederiksen BL, Osler M, Dalton SO (2012) Socioeconomic position and stage of cervical cancer in Danish women diagnosed 2005 to 2009. Cancer Epidemiol Biomarkers Prev 21: 835-842.

Jensen KE, Hannibal CG, Nielsen A, Jensen A, Nohr B, Munk C, Kjaer SK (2008) Social inequality and incidence of and survival from cancer of the female genital organs in a population-based study in Denmark, 1994-2003. Eur J Cancer 44: 2003-2017.

Jensen VM, Rasmussen AW (2011) Danish Education Registers. Scand J Public Health 39: 91-94.

Katz A, Eifel PJ, Moughan J, Owen JB, Mahon I, Hanks GE (2000) Socioeconomic characteristics of patients with squamous cell carcinoma of the uterine cervix treated with radiotherapy in the 1992 to 1994 patterns of care study. Int J Radiat Oncol Biol Phys 47: 443-450.

Kogevinas M, Porta M (1997) Socioeconomic differences in cancer survival: a review of the evidence. IARC Sci Publ 177-206.

Kvikstad A, Vatten LJ (1996) Cancer risk and prognosis in Norway: comparing women in their first marriage with women who have never married. J Epidemiol Community Health 50: 51-55.
Kvikstad A, Vatten LJ, Tretli S (1995) Widowhood and divorce in relation to overall survival among middle-aged Norwegian women with cancer. Br J Cancer 71: 1343-1347.

Lange T, Hansen JV (2011) Direct and indirect effects in a survival context. Epidemiology 22: 575-581.

Li X, Sundquist J, Calling S, Zoller B, Sundquist K (2012) Neighborhood deprivation and risk of cervical cancer morbidity and mortality: a multilevel analysis from Sweden. Gynecol Oncol 127: 283-289.

Lim JW, shing-Giwa KT (2011) Examining the effect of minority status and neighborhood characteristics on cervical cancer survival outcomes. Gynecol Oncol 121: 87-93.

Louwman WJ, Aarts MJ, Houterman S, van Lenthe FJ, Coebergh JW, Janssen-Heijnen ML (2010) A 50\% higher prevalence of life-shortening chronic conditions among cancer patients with low socioeconomic status. Br J Cancer 103: 1742-1748.

Low EL, Simon AE, Lyons J, Romney-Alexander D, Waller J (2012) What do British women know about cervical cancer symptoms and risk factors? Eur J Cancer 48: 3001-3008.

Lund R, Due P, Modvig J, Holstein BE, Damsgaard MT, Andersen PK (2002) Cohabitation and marital status as predictors of mortality-an eight year follow-up study. Soc Sci Med 55: 673-679.

Lynge E, Sandegaard JL, Rebolj M (2011) The Danish National Patient Register. Scand J Public Health 39: 30-33.

McCarthy AM, Dumanovsky T, Visvanathan K, Kahn AR, Schymura MJ (2010) Racial/ethnic and socioeconomic disparities in mortality among women diagnosed with cervical cancer in New York City, 1995-2006. Cancer Causes Control 21: 1645-1655.

Movva S, Noone AM, Banerjee M, Patel DA, Schwartz K, Yee CL, Simon MS (2008) Racial differences in cervical cancer survival in the Detroit metropolitan area. Cancer 112: 1264-1271.

Patel MK, Patel DA, Lu M, Elshaikh MA, Munkarah A, Movsas B (2010) Impact of marital status on survival among women with invasive cervical cancer: analysis of population-based surveillance, epidemiology, and end results data. J Low Genit Tract Dis 14: 329-338.

Pedersen CB (2011) The Danish Civil Registration System. Scand J Public Health 39: 22-25.

Quinn MA, Benedet JL, Odicino F, Maisonneuve P, Beller U, Creasman WT, Heintz AP, Ngan HY, Pecorelli S (2006) Carcinoma of the cervix uteri. FIGO 26th Annual report on the results of treatment in gynecological cancer. Int J Gynaecol Obstet 95(Suppl 1): S43-103.

Rodvall Y, Kemetli L, Tishelman C, Tornberg S (2005) Factors related to participation in a cervical cancer screening programme in urban Sweden. Eur J Cancer Prev 14: 459-466.

Seidel D, Becker N, Rohrmann S, Nimptsch K, Linseisen J (2009) Sociodemographic characteristics of participation in the opportunistic German cervical cancer screening programme: results from the EPIC-Heidelberg cohort. J Cancer Res Clin Oncol 135: 533-541.

Simard EP, Fedewa S, Ma J, Siegel R, Jemal A (2012) Widening socioeconomic disparities in cervical cancer mortality among women in 26 states, 1993-2007. Cancer 118: 5110-5116.

Singh GK, Miller BA, Hankey BF, Edwards BK (2004) Persistent area socioeconomic disparities in US incidence of cervical cancer, mortality, stage, and survival, 1975-2000. Cancer 101: 1051-1057.

Tammemagi CM (2007) Racial/ethnic disparities in breast and gynecologic cancer treatment and outcomes. Curr Opin Obstet Gynecol 19: 31-36.

Tan W, Stehman FB, Carter RL (2009) Mortality rates due to gynecologic cancers in New York state by demographic factors and proximity to a Gynecologic Oncology Group member treatment center: 1979-2001. Gynecol Oncol 114: 346-352.

Torres MA, Jhingran A, Thames Jr HD, Levenback CF, Bodurka DC, Ramondetta LM, Eifel PJ (2009) Concurrent chemoradiation in the routine management of patients with cervical cancer: does marital status matter? Int J Gynecol Cancer 19: 1107-1112.

This work is published under the standard license to publish agreement. After 12 months the work will become freely available and the license terms will switch to a Creative Commons AttributionNonCommercial-Share Alike 3.0 Unported License. 